\title{
Student teachers' first reflections on ICT and Classroom Learning: implications for Initial Teacher Education
}

\author{
Dr. Daniela Sime, University of Glasgow ${ }^{1}$ \\ Mark Priestley, University of Stirling
}

\begin{abstract}
This article explores student teachers' views of the use of information and communication technologies (ICT) in schools. There is limited research literature regarding the perceptions that such students develop in relation to the use of ICT in teaching while observing practice in schools. The paper offers an interpretive analysis of the opinions that a cohort of undergraduate student teachers at a Scottish University expressed in an online forum, following a period of school placement. As part of their Initial Teacher Education (ITE), the students were asked to post messages on the forum in relation to the factors that they perceived as promoting or hindering the use of ICT in schools. Perceptions that students held were found to be complex and varied. Students associated the use of ICT with changes in the nature of classroom relations, as well as a reshaping of learning and teaching. While they welcomed the introduction of ICT as a tool for modernising teaching, students identified a variety of factors that hinder this process. The paper finishes by identifying some of the implications for those working with student teachers in encouraging their development of reflective practice with ICT and enhancing their positive attitudes in relation to the use of ICT in schools.
\end{abstract}

Keywords: ICT use; student teachers; student attitudes to ICT; reflective observation; online forum

${ }^{1}$ Corresponding author. Glasgow Centre for the Child \& Society, University of Glasgow, 66 Oakfield Avenue, G12 8LS Email: d.sime@socsci.gla.ac.uk 


\section{The technologisation of schools and its social context}

To err is human--and to blame it on a computer is even more so.

(Robert Orben)

Technology has become a key mediator of human relationships not only in schools, but also in other fields, such as commerce, media and business etc. Family relationships are changing due to increased access by parents and children to technological devices. Home access to computers and other technologies is growing rapidly (Livingstone and Bovill, 1999; Livingstone and Bober, 2004). Computers and other related technologies have become symbolic goods (Cawson et al, 1995), and owning them is identified with social distinction and intellectual superiority. Parents are led to believe by companies (and schools) that investing in technology is a form of 'good parenting' (Buckingham et al, 2001) and that computers give children limitless options to learn, a claim that is still under debate in current literature. In the face of such trends, public perceptions of the benefits that computers and other technologies play in children's lives are varied: they range from total fascination and amazement at their power to circulate information to a form of latter day Luddism, characterised by fears of unseen dangers and risks.

Such societal phenomena are reflected within the education system. The impact of ICT is most evident at a policy-making level. For example, it has become in recent years a priority of policy makers in UK, where the present government emphasises the role that technology could and should play in transforming learning by making it more accessible to individuals everywhere through online tutoring and individualised programmes appropriate to each pupil's needs (DfES, 2002). This priority given to technology in mediating the reform of the content of education and in changing the types of interactions between teachers and pupils and pupils and pupils in schools anticipates a new, 'digital generation' of learners. Such a context generates new expectations and strategies, both for upskilling existing teachers, and for preparing newly qualified teachers to use ICT as part of their teaching. 
This paper examines the perceptions that student teachers in a Scottish University developed in relation to the use of ICT in schools, following a period of school placement. It draws on the analysis of messages posted by 82 secondyear students in an online discussion forum. The paper briefly examines the recent research developments in relation to teachers' and student teachers' attitudes to the uses of ICT in schools, before considering the data from our study. Based on the evidence emerging from our data, we examine how is ICT transforming teaching and learning in student teachers' perspective and what factors affect the successful use of ICT, in their views. We finally conclude with some implications for student teacher learning and training.

\section{Teachers and ICT}

Recent research (e.g. Waite, 2004) indicates that although teachers in schools show great interest and motivation to learn about the potential of ICT, in practice, use of ICT is relatively low and it is focused on a narrow range of applications, with word processing being the predominant use, and video/network conferencing, emailing and the Internet being rarely used. International research suggests that ICT as a tool to promote learning is not generally well embedded in teachers' practice (Cox et al, 1999; Pedretti et al, 1999; Zhao and Cziko, 2001) and that 'information technology in the classroom is used in an ineffective way and it has proven difficult to integrate within traditional curriculum settings' (Jules Van Belle and Soetaert, 2001:38) In the Scottish context, the evidence suggests a similar picture (Williams et al, 1998). Many teachers recognize a range of benefits for pupils and themselves in using ICT, but more often than not fail to integrate it in their teaching, continuing to 'teach ICT rather than teach with ICT'. In primary schools, teachers tend to use ICT to support classroom practice, while secondary school teachers use it more for professional development and personal use rather than for teaching. The same study showed that teachers who use a computer at home tend to use it more in classrooms and that differences exist between subject areas in the practice and attitudes towards ICT, with teachers of business management using it more and Mathematics and science teachers using it the least. 
Many reasons have been suggested for the failure of ICT to embed more completely in schools. Pelgrum (2001) reports on an international survey of teachers' perceived obstacles to using ICT and identifies three major factors: lack of resources, lack of knowledge and skills and pedagogical difficulties to integrate technology in instruction. The competence factor and teachers' confidence in their skills as a major factor that conditions teachers' willingness to integrate technology in their teaching is cited by other research (Williams et al., 1998; Mooij and Smeets, 2001). Dawes (2001) identifies the critical importance of the following factors as perceived barriers in teachers' use of ICT: ownership of upto-date technology; a sense of purpose for ICT use; adequate training; realistic time management; and inclusion in supportive communities or practice. Zhao and Cziko (2001:27) identify three conditions that must be fulfilled for teachers to be motivated and use ICT in their practice:

1. Teachers must believe that by using technology they are more likely to achieve a higher-level goal than through other means used ('effectiveness')

2. They must believe that if used, technology will not disturb the other highlevel goals that they want to achieve ('disturbances')

3. Finally, teacher must believe that they are in control, having the ability and resources to use ICT effectively ('control')

These authors suggest that once these conditions achieved, teachers will introduce ICT in their lessons. Cox et al (1999) talk about a 'technology acceptance model', explaining the interplay between external factors and perceived usefulness and ease of use as conditioning the use of ICT. Teachers were reported to include mainly external factors (training, time to explore software, new computers, appropriate software) when discussing their progress with using ICT for literacy activities (Waite, 2003). In the same study, almost $75 \%$ of the teachers considered that when using computers and the Internet, they had to change the ways in which they planned their teaching. This may suggest another factor that may act as a barrier in using ICT in classrooms, as teachers 
may require extra time to prepare a class. A teacher may have to book the computer suite or a laptop, decide activities suitable for computer use, check software in advance and have a contingency plan etc. Many of these issues can be neatly encapsulated by the practicality ethic articulated by Doyle and Ponder (1977). This suggests that teachers may oppose or fail to enact change even where it is congruent with their core values, should such change lack instrumentality (i.e. be difficult to enact) and if there are potentially significant costs (for example professional risks). The practicality ethic may be strengthened, and teachers thus motivated to use ICT, when there exists a supportive community of users among practitioners who can learn collaboratively by exchanging ideas either in face-to-face discussions or in online communities, through emails, discussions, and online staff boards etc. (Preston, 1999; Leask and Younie, 2001).

In summary, there seem to be four major issues identified by research for introducing technology in teachers' practice. These are:

- Beliefs: personal ideas about the contribution that technology can make to the processes of teaching and learning and classroom management;

- Experience: own training and ICT skills, abilities to control ICT use in the classroom and cope with technical failure;

- Resources: available technologies in schools and ownership of own computer at home;

- Community: membership to a network of colleagues who can provide support, encourage use and constitute a learning community.

\section{Student teachers and ICT}

Fewer studies exist on the beliefs and attitudes that student teachers hold in relation to their use of ICT in their teaching practice. Students have been reported to attribute their progress in using ICT for teaching mainly to their use of computers for personal purposes at home, at work, and in university (Cuckle et al, 2000; Trushell et al, 1995). In another study that involved a longitudinal 
monitoring of students' learning with and about ICT (Taylor, 2003), students reported that they consciously used a repertoire of learning strategies whilst developing their ICT skills. They perceived several factors as affecting their progress, including previous experience, match of learning opportunities with their preferences and software attributes. A later study by Taylor (2004) provides a helpful typology to explain the development of sophistication in student teachers' thinking about the use of ICT in teaching; this study highlights three factors - university-based teaching, assignments and teaching using ICT - as being significant in this development.

Student teachers are now required to not only show good ICT skills, but also to be able to include ICT in their teaching in a manner which enhances children's learning. In Scotland, the SOEID guidance on the use of ICT in teacher training (SOEID, 1999) proposes five categories of skills and knowledge that students should develop during their teacher training In relation to the guidelines, there is now relevant literature that recommends ways of ensuring that student teachers are prepared to teach using ICT. Several authors (Beyerbach et al, 2001; Clift et al, 2001; Pritchard, 2001; Simpson et al, 1999) underline the importance of the following aspects of training future teachers to use ICT:

- The modeling of ICT use by ITE tutors and teachers observed during school placements;

- Opportunities at university to use ICT in their own learning and to practice the use of ICT in teaching;

- The existence of a community of users (mentors, other students, teachers in school) that can offer support and guidance if needed;

- The provision of a compulsory element within the ITE programme to promote use among reticent students;

- The provision of ideas and practical activities, with direct relevance for the teaching of subjects.

The rapid advance of technology means that the level of ICT skills of many students on entry to higher education is advanced (Simpson et al, 1999). In this 
sense, many of the students in our study took on a paradoxical role of the 'expert novice' when placed in schools. While they lacked experience of classrooms and learning, many possessed technical ICT skills that far exceeded those of the teachers with whom they were placed, and this gave them considerable kudos, despite their 'rookie' status. Such a situation placed many of them in a unique position to observe and comment upon the ICT use they encountered on placement. Our study seeks to draw upon these reflections. We need to know more about the students' conceptualisations of pedagogical uses of ICT and about their understandings of the ways in which ICT affects the processes of learning and teaching. This approach would inform teacher educators about the formative processes and stages that students go through and would enable the identification of concrete ways of supporting their learning to teach with ICT.

\section{The design of the study}

To examine the perspectives that student teachers develop in relation to the use of ICT in schools and its contribution to the processes of teaching of learning, we explored the views expressed by 82 students in an online discussion forum. The cohort comprised a group of second year student teachers on a four-year secondary ITE programme, with a variety of teaching subjects. The cohort comprised both recent school leavers and more mature students.

Based on the online discussion data, the study investigates the following research questions in relation to this paper:

- How do students understand the processes of teaching and learning when ICT is involved in teaching?

- What are the factors that affect students' perceptions of ICT use?

Data collection

The integration of ICT into routine teaching situations was first systematically observed by students during an observational placement in primary schools. Students were subsequently asked to participate in two online forum discussions during the academic year, their participation being facilitated by tutors. Each 
forum lasted about two weeks. The study is based on the data generated as part of the programme, through the contributions made online. Students were asked to reflect on professional practice in using ICT based on their own experiences and observations in schools and to evaluate critically the lessons observed.

The use of the online discussion contrasts with the more traditional methods of student inquiry adopted in other courses on the programme. Students were required to attend several lectures, and had a list of set readings, but face-to-face seminars were replaced by the online discussions. To protect the anonymity of the participants, the forum is now closed and students are not named in the present paper. Consent forms were obtained from the individuals whose contributions are quoted in this paper.

Students were divided arbitrarily into four discussion forums organised and moderated by the course tutors. Each forum was 'public' to all students, who were encouraged to read contributions made by their colleagues in other forums, while they could post messages only in the specific forum to which they were allocated. Students posted between one and twenty messages each, the average number of postings being 5.5 messages per student. They knew that there was a compulsory dimension to the discussion, as they all had to make 'at least one meaningful contribution' based on their observations on schools in order to pass the unit. Contributions had to address the topic of ICT, be supported by ideas from readings and build on issues raised by the other participants. The focus of the discussions was initially identified by the tutors (e.g. use of ICT to promote learning, factors that hinder the use of ICT in schools, issues of safety online), but then students were able to bring into discussion their own ideas or interests. Across the discussion forums, several topics were considered, such as funding for computers in schools, gender divisions in using technology among teachers and children, professional development of teachers in schools in relation to ICT training, funding for ICT in schools, other ICT uses in schools apart from computers, social class distinctions perpetuated by differentiated access to technology and moral aspects of internet use by children. 


\section{Data analysis}

When analysing the messages posted by the students on the discussion forum, we had the following objectives:

- To identify the variety of computer uses that students observed as part of their training in schools and the conditions that they perceived as facilitating the effective use of ICT;

- To discuss the advantages and disadvantages that students perceived in relation to the use of computers in schools;

- To investigate the ways in which these advantages and disadvantages are linked to the issues of teaching and learning;

- To identify the potential formative effect of this type of reflective action research on developing students' attitudes and understanding towards the use of ICT as a teaching tool.

Messages were analysed using a form of recursive comparative analysis; this refers to a process by which the findings that emerge from the data are constantly tested and refined to take account of all the relevant data. In total 456 messages were included in the sample. In analysing, we followed the following steps:

- Read messages from one of the lists. This included a process of making notes on the strands of data, looking for possible themes, labelling extracts, articulating concepts and themes, looking for examples of judgements and factors influencing these judgements;

- Identify points of similarity and/or difference among various messages in relation to the research questions. This was a process of labelling and relabelling and grouping together similar extracts to strengthen the themes developed;

- Generate possible theories/ findings to reflect answers to the research questions. After a proportion of the data was coded, we looked at categories to make sense of the main ideas contained in the messages; 
- Test the theory against a new set of messages from another sample. This process allowed for ideas, developed in relation to the themes and theories identified, to be checked against other strands of data; it also allowed a further development of some themes and restructuring of others;

- Repeat the above process until all data have been examined and all theories were tested against the data.

\section{Discussion}

A number of strands in student teachers' understandings of the role that ICT plays in teaching and learning could be identified from the data. These were:

- Awareness of the possibilities to transform teaching and learning afforded by the uses of ICT;

- Understanding of the factors that condition the successful use of ICT in the classroom;

- Ideas about strategies for planning and integrating ICT tools in teaching certain subjects;

- Ideas about managing children and technology to ensure successful teaching and learning;

- Thinking about the need to differentiate and consider individual pupils' needs, by taking into account their competence with ICT, home access and interest in using ICT;

- Reflection on own practice and the role of observing ICT use in schools in configuring one's identity as a teacher.

The messages analysed indicate that all student teachers had some understanding of the potential that ICT has to enhance the processes of teaching and learning. This understanding was evidenced in the online messages not only at a generic level, as informed by reading and observed practice, but also at a level specific to particular lessons taught or observed in school placements. The discussion boards reflected diverse, critical and sophisticated thinking about the 
potential that ICT has to transform teachers' practice, a fact which surprised the tutors, considering the relatively early stage in the ITE programme.

The remainder of the paper draws upon an interpretive analysis of the first two strands identified above; we summarise the ideas expressed by the students and illustrate some of these, before briefly discussing the potential of using this type of interaction as a formative process of student teacher development.

\section{How is ICT use transforming teaching and learning?}

Students were divided in their attitudes towards the potential of ICT to enhance teaching and learning. Some of them were unconditionally supportive and perceived ICT as a successful tool at all times and in all circumstances:

In a modern, digital age world, it is important that children are exposed to ICT in school as much as possible. After all, they may not be exposed to it at home. ICT use is required in virtually every job or business and without exposure to it, would we as teachers being doing our job properly (...)? I think not.

The majority of students, however, challenged an unconditional acceptance of ICT in classes and reflected on the necessary conditions for making its integration useful. The following two messages illustrate this:

ICT is a technological development that reflects the new society and has its place within education. However, as with many new initiatives, ICT obviously has its problems that over time will be addressed. Meantime, ICT should continue to be promoted to assist with education and learning.

I will heartedly agree with anyone who states that ICT is a valuable tool for both teaching and learning - speaking as someone who got the last lessons plan for my teaching from the Internet- but I can't help feeling that the emphasis on the use of ICT detracts from other current 'sexy' education issue - socialisation. I believe that developing teachers' social and counselling techniques is a greater priority than their ICT skills.

Although having spent a limited amount of time in the classroom (in most cases only the three weeks placement since leaving school), students were discerning in their discussions of the potential of ICT for teaching and learning, giving several examples of what they considered as good practice. In particular, students noted the instances when technology was integrated in teaching and 
used as a tool in meaningful activities rather than as an end in itself. One student noted that:

The school I attended for my placement used ICT in all subjects. For example, they have a Scots evening coming up and the pupils have all been typing up their own poems to recite on the day. They used the internet the research for information on Scottish history. I also found their Maths software amazing, the children were very keen and seemed to enjoy their maths lessons, something I don't recall doing in my years as a pupil.

Even student teachers who were more sceptical about the potential of ICT to enhance learning or to support teaching accepted that technology is nowadays an important mediator of social interactions and teachers need to integrate its use in their practice. They focused on the potential that computers have in transforming the teachers' role and in improving the quality of teaching. Students made comparisons between situations in which teachers used more traditional, teacher-centred methods of teaching and the situations in which they adopted ICT and more participative methods. They tended to reflect on the impact that ICT had on reshaping classroom dynamics and ultimately on the relationship between teachers and pupils.

In my school, ICT was used whenever the teachers felt that they could enhance pupils' learning. (...) The children used CD-ROMs and software packages in groups of two or three and thins further enhanced their competence and confidence, as they were supporting each other. Teachers were also seen as 'help at hand' if needed and they thought that children did not mind as much if the computer would tell them when they were wrong. Children were very motivated and were often learning without realising it.

Classes in which ICT was integrated effectively in meaningful activities were perceived as being more enjoyable for the learners and with a greater potential to provide them with memorable learning experiences. Learners were seen to be more engaged and involved in the processes of learning when their exploration of the ICT tools was framed by a coherent input from the teacher and by constant guidance and assistance, if required. When learners were seen to engage with the task, bring to the class new ideas found through Internet searches and learn at their own pace, students thought that ICT use was successful. In these terms, 
they usually commented on the importance of differentiation and the transformation of the learning process at the individual rather than collective level, reflecting on pupils' individualised ICT competences and learning needs.

The primary four class which I worked with used accompanying literacy world software. Each pupil had their own site which they could go on to. The teacher had put each pupil into his or her ability group and set out the task they were to do. She would then support individual learners with what they needed to make progress in their own learning or with their ICT skills and would check at the end everyone's work.

My school had a PC in each classroom (...) which was used quite lot by one boy who had extreme difficulty in writing/copying things off the board. He was therefore able to use the PC to write things up, print out his work and stick it in his jotter. This seems to be a very simple use of a PC, yet it made it possible for the pupil to keep up with the rest of the class, rather than fall behind.

However, very few instances of responsive and personalised learning experiences were directly reported by the students. There seemed to be an acceptance of the fact that teachers have limited opportunities and skills to provide children with personalised assistance and that the use of computers in schools drags behind children's home use.

One of the interesting aspects that emerged from the students' messages was their ability to empathise with both teachers and pupils. They were able to reflect on the impact that technology and its use would have on the pupils' learning, by judging the task at hand and identifying themselves with the pupils, often through their own school experience or through observations of their own children at home. When they were under the impression that technology was used for its own sake, and did not add value to learning in the class, students did not hesitate to criticise:

Did anyone find they [the teachers] were just sort of using the equipment because they had to, so that they could say 'yeah, we've used to computer for 30 mis (sic) today, well done', when there was no actual reason for doing it? I think it should be embedded in the classroom with other tools for learning and they should show the kids how to use them to facilitate learning. In my school, the things kids were doing on the computer were really tedious and boring. 


\section{What factors affect the successful use of ICT in schools?}

Students identified a range of factors that they perceived as conditioning the successful use of ICT in the classroom. These factors can be grouped into three categories:

(a) Physical factors, i.e. that refer to the provision of ICT resources in schools;

(b) Human factors, i.e. that refer to teachers' perceived attitudes towards ICT use, their ICT competence and specialised training;

(c) Cultural factors, i.e. that refer to the more general attitude promoted towards the use of ICT at school level and at the community level.

In their first weeks of classroom observation, students tended to emphasise the physical, resource-related barriers that they perceived as affecting the use of ICT in the schools that they visited. Discussions highlighted the difficulties encountered by teachers in some schools, where the number of computers was insufficient, the computers were old, difficult to operate and crashed frequently, generating constant disturbance during classes. The following three messages are typical of the comments placed in the discussion forums:

My primary placement was in a really small school and they had difficulties with space. The computer suite was in the library, but you could only have six or seven pupils in at a time, once a week. This meant that it took weeks before the whole class had completed a task.

The ICT suite was hardly ever used as it had only five computers in it. This was a major problem, as the teacher was not allowed to send children in that room and leave the class unsupervised. Therefore, the children would use the two computers in the class between 30 pupils. What a terrible waste of resources!

In my school, the main hindering factors were simple impracticalities like lack of permission slips to use the internet, time (a major factor), some equipment took a while to set up and that put the teacher off, as she felt there was little time in her day already, so she had to prioritise reading and writing.

Significantly, students started to identify themselves with the teacher's role and reflect critically on the obstacles that teachers could not surmount in promoting 
the use of ICT. While some of them reacted by criticising the lack of support that schools receive from local authorities through lack of sufficient funding, others started to things of ways through which schools could change practice to adapt to the level of existent resources. They considered better ways of organising the computer suites, methods for integrating individual use of computers in the classroom, and ways of getting parents and local communities involved in improving the provision of ICT in the school.

However, on the whole students believed that most placement schools had a satisfactory level of resources. These schools had either sophisticated computer suites with Internet access and efficient intranets, or computers placed directly in classrooms. When the provision of resources was seen as satisfactory, but the integration of ICT in classes was limited, students tended to reflect on the teachers' personal attributes as representing the main barrier to innovative ICT use. Such attributes include teachers' attitudes towards the role of ICT in schools and their own skills and confidence in using ICT as a tool for teaching. Students often related teachers' attitudes to their own experience of using ICT. Some students expressed the view that they would be reluctant to risk a lesson by using a tool with which they were not familiar. Others were less sympathetic, believing that failure to use ICT in class deprives children of an important skill for life. The following comments concern the effects that teachers' negative attitudes and lack of skills can have on ICT use:

In my placement, all the teachers had completed the ECDL, but many still felt ill at ease at trying any ICT use out with a timetabled computing lesson. In-service training run by the deputy head tried to make them more confident, but in reality the teachers I spoke with feared the lesson going belly-up because of technical difficulties that the teacher could not fix. I would question then the usefulness of teacher training that cannot add any value to their teaching.

I found ICT to be greatly underused as many others have found in their school visits. The problems that I came across were like in many other schools, lack of teacher knowledge and experience, loss of teacher confidence through using ICT, lack of adequate training and support. The school had a high tech computer suite, of which few could take advantage. 
I thought that the school hastily took the ICT route without preparing their way.

My first week was with a $\mathrm{P}^{1}$ class and the teacher saw ICT more like a chore than a tool. My other two weeks were in the P6 class, where children were always working on computers. I think the use of ICT in each class depended on the competency and confidence of the two teachers. Teachers with appropriate training are confident to do various tasks with children on the computer, teachers without training will try and avoid ICT whenever possible.

What should be emphasised from these comments is the significant difference that a teacher's confidence and ICT expertise can play in configuring the type of teaching and learning that takes place in a class. Students tended to perceive the teacher as the main catalyst in implementing and promoting the purposeful use of ICT in their classes. Even when resources were limited and access to computer suites was problematic, students thought that the individual teachers' attitude was the vital factor in determining ICT use. One of the students said about the teacher she worked with:

I observed a primary school teacher who said to me that she did not feel the need for children to be getting taught ICT as it was taking valuable teaching time from Math and Languages. How can ICT be promoted by teachers who have this kind of attitude?

Several students commented on teachers' general attitudes towards the use of ICT. They thought that many teachers were negative towards the potential of ICT to support their teaching and saw its use as an 'extra chore'. Their opinions seemed to be informed by a perception that ICT seemed to be a bolt-on activity, and that the use of computers took place in isolation from the topics taught. In many cases, children were observed to gain access to the computer suites as a 'reward' for work completed elsewhere in the curriculum. When discussing the lack of integration of ICT in teaching, most students tended to identify the teachers' lack of training and ICT skills as the main problems. Individual teachers were also perceived as having the power to model children's attitudes towards ICT and their attitude in this sense was considered as crucial. When teachers 
were enthusiastic and dedicated to finding ways of using ICT in teaching, and gave pupils meaningful tasks on the computer, pupils were thought to be more involved in their learning with ICT.

The third set of factors discussed by students in relation to the observed use of ICT in the schools concerned the culture of promoting ICT at the school and local community level. Many students considered that the ways in which the school organised the use of ICT influenced its micro-use at the class level. Some schools were thought to promote ICT use through strategies such as encouraging teachers' computer use, providing teachers with organised opportunities for training, giving them opportunities to exchange ideas about integrated ICT use and providing a support teacher or technician. Students thought that, in this kind of environment, even the most reluctant teachers were more likely to attempt to learn to use ICT. Several messages reflected such an experience:

The teachers in my placement were all just newly qualified and very good at getting children involved in using ICT. They were still to receive more training in using 'class in a box' laptops, but still encouraged the children to use them. They were however constantly encouraged by the head teacher, who saw the advantages of ICT.

While the school I was in had an ICT co-ordinator, the teachers were all quite comfortable with their ICT skills. They had even run an in-school training by the more qualified staff to assist those who wanted to learn more. They also opted for ICT courses as part of their CPD. One teacher said that even the most technophobe teachers were won over due to the supportive atmosphere between staff

By contrast, teachers who were isolated ICT users in a community of non-users were thought to be under pressure to conform and return to more traditional, nontechnical based methods of teaching. Students often talked in these circumstances about a 'divide' between the staff in terms of ICT skills, and they added other factors that were thought to contribute to that divide, such as teachers' age and attitudes:

My school consisted of a divide in teaching groups, those who could use ICT and those who couldn't! 
The teachers who were a bit older and they would stay clear of the computer rooms. I eventually asked one of the teachers why this was and her response was that like herself, the other teachers did not have the skills in using the computers and an interest in finding out about them.

At my school, the staff were all very experienced teachers, but mostly uncomfortable with using computers themselves. I felt that they would have pushed for more computer time for the pupils if they had felt more comfortable with ICT and the school would have encouraged them more. ICT will never be encouraged by someone who is not comfortable in using it themselves.

The observation of cultures in which teachers were reluctant to use ICT made several students reflect on the ways in which these teachers' beliefs could be challenged and attitudes changed. Two mature students suggested strategies to change practice:

Regarding age and attitudes towards computers, there did seem to be some correlation between these in my school. Older teachers were far more reluctant to use it. For those of us who are not comfortable with technology, it is important to be eased in gently. ICT has to be promoted to technophobes as positive as time saving. It is also really important to have adequate support for staff.

The younger teachers are more open-minded towards the use of ICT. It reflects a fact that there is a need for ICT to be promoted not only as benefiting learning, but also by benefiting teaching.

If teachers were given clear examples of the advantages of using ICT and opportunity to learn how to use it constructively (without having to pay for it), there would be a majority uptake. Most teachers strive to make their lessons more interesting and up to date and would welcome any support to reach that.

Not all students made such reflective comments on possible ways of improving attitudes and practice with ICT. However, most of them did indicate in their postings a relatively well-developed understanding that included thinking about both the objective and the subjective factors that affect ICT use in schools. By reflecting on their observations, students seem to develop their own practical theories about the best ways of promoting the use of technology at macro-level 
and many of them hold strong convictions that the school as a culture has the power to influence individual teachers' practice and beliefs. Nevertheless, students did not ignore the immediate, contextual factors, such as the provision of resources, or the individualised aspect of teaching with ICT, as mediated by each teacher's skills, confidence and attitudes.

\section{Implications for student teacher learning}

The students identified a range of experiences from their practice in schools as having helped them to contextualise their understanding of the uses of ICT in teaching and, by implication, representing contexts for the processes of becoming a teacher. Almost all students made links in their comments between the theory learnt in the university-based course, their assignments and the experience of observing and teaching with ICT. Students were reflective about the processes that prompted the development of their understanding of teaching and learning using ICT, although they were just novices in seeing what was happening in the complex world of the classrooms they observed. The school experience seemed to provide an authentic environment for contextualising the theory and making learning a more personal experience. Each individual student experienced a unique school, with a particular culture of promoting (or not) the use of ICT and these unique experiences appeared to influence the students' own attitudes about the role of ICT in teaching. The online forum provided in this sense a useful medium for validating these ideas and sharing with the others personal experiences. By doing this, participants transformed these experiences from personal and often ephemeral knowledge into shared and memorable events that came to constitute a body of knowledge, evolved through group reflection and co-construction.

As student teachers were taught in their course ways of integrating ICT in teaching subjects, many of them found themselves in between two cultures: the culture of the teacher training course that underlines the importance of ICT as a teaching tool in all subjects, and the culture of the schools where they had to work and which still tends to perceive ICT as a separate subject. Often students found themselves as influencing the environment which they were supposed to 
observe, as teachers in schools asked them to become involved and make contributions or changes to the ways in which ICT was used:

One teacher who had asked me on a number of occasions to aid them with their particular ICT difficulties had asked me how would I deal with the problem of introducing ICT to old fashioned teachers.

Very few teachers at my school placement were confident with ICT matters and felt determined that children knew more about ibooks ${ }^{2}$ than they did. They welcomed me with open arms as I taught ICT lessons every day, great experience for me, but I felt really bad for teachers with so much knowledge in other areas that had not been trained properly in ICT.

It is difficult to estimate the extent to which the type and quantity of lessons observed influenced the students' understanding of the effective use of ICT in teaching and learning and impossible to predict the influence that observed practice will have in the participants' own teaching. It is however evident that most students in the cohort had experienced both positive and negative situations of ICT use within their placement schools, and during this experience their ideas became grounded rather than being theorised in academic input or papers. The participants' ideas became more sophisticated in time. Reflection on personal practice, whether teaching or observation, seems to promote learning more effectively than does decontextualised seminar discussion about the potential of ICT to improve teaching and learning.

This type of online discussion seems to be a useful tool for peer mentoring and professional development. Several learners expressed the view that the online discussions provided a medium for verifying their own hypotheses about the role of ICT; they represent a medium for the development and articulation of their emerging professional understandings of theoretical and practical issues related to the use of technology in schools. These professional conversations proved to be more than online seminars; they generated opportunities for individuals to validate ideas inspired by observed practice. Students cooperated as a community in building a set of ideas that were developed through collaborative negotiations and the forums appeared thus to be influential in determining 
individual attitudes to ICT use. The data accumulated over almost a year made it obvious that the student teachers were actively developing their attitudes to the use of ICT in teaching. They did not appear as passive recipients of learning, but were seen to draw on a wide range of sources to help with their professional development. The contexts in which they found themselves as learners, whether at university, in school placements or accessing the online forum from home, had at times constrained and at times enabled their attitude formation in relation to the role of ICT in teaching and learning and to their own identity as future teachers. However, the fact that they were able to reflect on the factors specific to each of these circumstances empowered them in the learning process and made them active and reflective learners.

The evidence collected suggests that ITE programmes should take account of a range factors and processes when encouraging students to become competent and confident users of ICT in their teaching. It is important to note that not all the factors identified will affect all individuals equally, and that some factors (e.g. the quality of ICT provision in placement schools) is largely outside the control of programme organisers.

The first set of factors concern previous experience and beliefs about ICT. It is reasonable to assume that students who have more experience in using ICT in their own learning and personal life will have a more sophisticated understanding of the benefits of technology in the classroom. A sound foundation of generic IT skills (i.e. training on basic and commonly used computing packages) is thus a useful addition to the early stages of an ITE programme, and one that will facilitate the development of a capacity to teach using ICT.

The second set of factors appears to be those related to the ITE environment in which learning to teach with ICT is promoted. These can be formal activities, such as lectures about the benefits of ICT, or more informal ones, such as help from a more experienced peer, classroom observations or online discussions. In order to be influential, these inputs need to be flexible enough to allow for individual reflection and provide suitable scaffolding for learners. Students often 
talked about the need to get the information from the lecturers and then needing time to make up their own mind and reflect on what they were taught; similarly, when observing a class, they were prompted to try out in their own teaching ideas that emerged after reflecting on what went well or what was missing in observed teaching with ICT.

The third set of factors that appear to influence the students' decisions to teach with ICT concerns the specifics of the school environment and culture. There are two aspects to this. First, negative experiences of ICT in schools (e.g. difficulties with equipment) seem to influence later decisions in terms of teaching with ICT. Second it is likely that when entering the teaching profession, students, even with good ICT skills, will hesitate to apply them in teaching if the physical, human or cultural factors in the school are not adequate for an efficient integration of ICT in classes, especially if their experience of using ICT to date has been blighted by problems. On their school placements, many students expressed a desire to adapt to the school environment, and fit in with the existing ICT culture of the school. When they were asked to use their advanced skills in supporting children and staff, they were keen to do so, but in other circumstances, they rarely challenged routines and existing practices. This is also likely to be the case when

entering a new school environment as a newly-qualified professional; ultimately the degree to which new practitioners use ICT in their career will probably depend to some extent on the culture and environment of the school in which they enter to practice.

\section{Conclusions}

This study indicates that student teachers have various ideas about the role of ICT in the classroom and about its potential to influence teaching and learning. These ideas tend to be shaped by a variety of factors, an important one being the nature of practice observed in schools. The school placements offer opportunities to reflect on theory and contextualise it and also provide an external stimulus for the development of pedagogic thinking. Such opportunities need to be varied in the case of each student to provide a variety of stimuli throughout the training 
period and to allow development of pedagogical skills. Students also need opportunities to develop beliefs and practical theories about the role of ICT, and the online discussion forum provides a good opportunity for this.

These research findings suggest a number of points that are worthy of consideration by those encouraging student teachers to use ICT:

- The study shows that student teachers are very active in developing their attitudes and ideas about efficient uses of ICT in schools, a perspective that has been under-emphasised by previous research in this field. By providing opportunities to observe practice and by encouraging reflection (through mechanisms such as online forums), educators and teachers can foster a medium in which students may develop their practice and attitudes in a proactive manner. Positive attitudes to the role of ICT in teaching are crucial in influencing teachers' decisions to use technologies in their teaching. The development of such attitudes during the teacher training programme appears to be a very dynamic process, as students' beliefs and hypotheses about the uses of ICT are challenged by tutors, the peer community and by classroom observations on a regular basis.

- The potential of online discussion forums to function as efficient tools for professional development of student teachers needs further investigation. However, several advantages have been identified by the current study. Online forums can provide an interactive medium for verifying own hypotheses about the use of ICT in classrooms and flexible access to a community of support. The forum represents a mediator for the development of the sort of community of practice identified by writers such as Dawes; such a community potentially exerts powerful influences in shaping individual attitudes to the uses of ICT. Unlike the learning logs that many student teachers currently use for reflection, online forums provide quick validations of ideas, feedback from a community and immediate support. The success of the forums may depend however on factors such as the participants' commitment and ICT skills, tutors' mediation skills and the extent to which the forums are utilised by the general student population. 
- Students, like teachers, often express their lack of confidence in their ICT skills and this implicitly affects their attitudes towards the use of ICT in their teaching. Although many ITE programmes provide appropriate support for students to develop their skills, it is important that the development of ICT pedagogies are underpinned by a reasonable level of generic IT skills. Lack of such skills may generate ICT-phobia and lead to negative ideas about the relevance of ICT as a tool for learning. In line with the conclusions of Zhao and Cziko (2001), our research suggests that confidence in ICT use is important, but that it is to some extent underpinned by competence.

- Programmes should contain opportunities to use ICT in practical setting, either through school placement, microteaching ${ }^{3}$ or role playing scenarios. These opportunities should enable further occasions for reflection on solutions to obstacles to using ICT in teaching and consideration of when it is appropriate to use ICT to support learning.

The study clearly highlights tensions between the idealised world of ICT use reflected in policy documents and the aspirations of teacher educators and students, and the harsher realities of schools, where ICT use is often more embryonic. The challenge for the new teachers is how to retain their enthusiasm for ICT in the face of the 'culture shock' they are likely to experience in many schools: schools that are still at the initial stages of experimenting with using computers in labs, with often limited integration in teaching and learning. Our research suggests that this type of experience may be a barrier to the effective use of ICT by enthusiastic new teachers; even where pedagogic use of ICT is strongly congruent with the values of the student teachers, a lack of instrumentality and potentially high professional and personal costs are clearly issues facing them (Doyle and Ponder, 1977). Substantive discussion of this issue is clearly beyond the scope of this paper, and further research is needed to explore how new teachers adapt to the new school culture and how schools capitalise on the knowledge and skills that newly qualified teachers bring when entering the profession. 


\section{Footnotes}

1. In Scotland the prefix ' $P$ ' precedes the school year for primary school pupils ( $P 1$ to $P 7$ ), and the prefix ' $S$ ' is used to denote the year in secondary schools (S1 to S6).

2. 'iBooks' are Apple Macintosh laptop computers.

3. 'Microteaching' refers to small scale lessons (e.g. simulated lessons to peers, or lessons to small groups of children in a controlled environment).

\section{References}

BEYERBACH, B., WALSH, C. and VANNATTA, R. (2001). From teaching technology to using technology to enhance student learning: Preservice teachers' changing perceptions of technology infusion, Journal of Technology and Teacher Education, 9(1), 105-127.

BUCKINGHAM, D., SCANLON, M. and SEFTON-GREEN, J. (2001). Selling the digital dream: marketing educational technology to teachers and parents, in Loveless, A. and Ellis, V. (eds), ICT, Pedagogy and the Curriculum subject to change, London: Routledge Falmer, 20-41

CAWSON, A., HADDON, I. and MILES, I. (1995) The shape of things to consume, Avemury: Aldershot.

CLIFT, R., MULLEN, L., LEVIN, J. and LARSON, A. (2001). Technologies in contexts: Implications for teacher education, Teaching and Teacher Education, 17, 35-50.

COX, M., PRESTON, C. and COX, K. (1999). What factors support or prevent teachers from using ICT in their classrooms? Available at www.leeds.ac.uk/educol/documents/00001304.htm

CUCKLE, P., CLARKE, S. and JENKINS, I. (2000) Students' Information and Communication Technology skills and their use during teacher training, Journal of Information Technology for Teacher Education, 9(1), 9-22.

DAWES (2001) What stops teachers using new technology? In Leask, M. (ed.) Issues in teaching using ICT, London:Routledge, 61-79.

DfES (2002). Young people and ICT, London: DfES.

DOYLE, W. and PONDER, G.A. (1977). The Practicality Ethic in Teacher Decision-Making, Interchange, 8(1), 1-12

JULES VAN BELLE, G.C. and SOETAERT, R. (2001). Breakdown into the virtual user-involved design and learning, Journal of Technology and Teacher Education, 9(1), 31-42.

LEASK, M. and YOUNIE, S. (2001). Building online communities for teachers: Issues emerging from research, In Leask, M. (ed) Issues in teaching using ICT, London: Routledge, 223-232. 
LIVINGSTONE, S. and BOBER, M. (2004). UK Children go Online- Surveying the experiences of young people and their parents, ESRC Report

LIVINGSTONE, S. and BOVILL, M.(1999). Young people, new media: report of the research project: Children, young people and the changing media environment, London: London School of Economics and Political Science

MOOIJ, T. and SMEETS, E. (2001). Modelling and supporting ICT implementation in secondary schools, Computers and Education, 36, 265281.

PAPPERT, S. (1996). The connected family: bridging the digital generation gap, Toronto: Stoddart

PEDRETTI, E., MAYER-SMITH, J. and WOODROW, J. (1999) Teaming technology enhanced instruction in the science classroom and teacher professional development, Journal of Technology and Teacher Education, 7(2), pp. 131-143.

PELGRUM, W.J. (2001) Obstacles to the integration of ICT in education: Results from a worldwide educational assessment, Computers and Education, 37, 163-178.

PRESTON, C. (1999). Building online professional development communities for schools, professional associations and LEAs, In Leask, M. and Pachler, N. (eds.), Learning to teach using ICT in the secondary school, London: Routledge, 210-226.

PRITCHARD, A. (2001). Meeting the requirements of the Initial Teacher Training National Curriculum for the use of Information and Communications Technology in subject teaching, with one year's cohort of postgraduate primary students, Journal of Technology for Teacher Education, 10(3), 293-308.

SIMPSON, M., PAYNE, F., MUNRO, R. and HUGHES, S. (1999) Using Information and Communications Technology as a Pedagogical Tool: Who educates the educators?, Journal of Education for Teaching, 25(3), 247262.

SOEID (1999) Guidelines on the use of Information and Communications Technology (ICT) within courses of Initial Teacher Education, Edinburgh: SOEID

TAYLOR, L. (2003) ICT skills learning strategies and histories of teacher trainers, Journal of Computer Assisted Learning, 19, 129-140.

TAYLOR, L. (2004) How Student Teachers Develop their Understanding of Teaching using ICT, Journal of Education for Teaching, 30(1), 43-56

TRUSHELL, J., DAVIDSON-PAYNE, C. and SLATER, A. (1995) Factors affecting development of IT use on partnership PGCE course, Computers and Education, 25 (3), 139-149. 
WAITE, S. (2004) Tools for the job: a report of two surveys of information and communications technology training and use for literacy in primary schools in the West of England, Journal of Computer Assisted Learning, 20(1), 1121

WILLIAMS, D., WILSON, K., RICHARDSON, A, TUSON, J. and COLES, L. (1998) Teachers' ICT skills and knowledge needs, Edinburgh: SOEID

ZHAO, Y. and CZIKO, G.A. (2001) Teacher adoption of technology: a perceptual control theory perspective, Journal of Technology and Teacher Education, 9(1), 5-30 